\title{
Effects of High Pressure on the Textural and Sensory Properties of Minced Fish Meat Gels for the Dysphagia Diet
}

\author{
Keiko Yoshioka1*, Ai Yamamoto1, Yasuyuki Matsushima², Kenji Hachisuka², \\ Yoshihide Ikeuchi ${ }^{3}$ \\ ${ }^{1}$ Department of Nutritional Sciences, Faculty of Nutritional Sciences, Nakamura Gakuen University, Fukuoka, \\ Japan \\ ${ }^{2}$ Department of Rehabilitation Medicine, University of Occupational and Environmental Health, Kitakyushu, \\ Japan \\ ${ }^{3}$ Graduate School of Agriculture, Kyushu University, Fukuoka, Japan \\ Email: 'Yoshioka@nakamura-u.ac.jp
}

Received 15 June 2016; accepted 22 July 2016; published 25 July 2016

Copyright (C) 2016 by authors and Scientific Research Publishing Inc.

This work is licensed under the Creative Commons Attribution International License (CC BY). http://creativecommons.org/licenses/by/4.0/

(c) (i) Open Access

\section{Abstract}

A new product of minced fish meat with high pressurization was produced for individuals with difficulties in mastication and swallowing and for elderly people on a dysphagia diet. Minced fish meat was added to distilled water at ratios of 1:0.5, $1: 1$ and $1: 1.5$ by mixing with $1.5 \% \mathrm{NaCl}$. Half of the samples were modified by heating (H-gels) and half by high pressure at $400 \mathrm{MPa}$ for $20 \mathrm{~min}$ (P-gels). The hardness of the $\mathrm{H}$ - and P-gels was 0.97 to $2.83\left[\times 10^{4} \mathrm{~N} / \mathrm{m}^{2}\right]$ and 2.25 to $10.03\left[\times 10^{4} \mathrm{~N} / \mathrm{m}^{2}\right]$, respectively. For SDS-PAGE analysis, low-molecular-weight proteins in the P-gel were released more easily than those in the $\mathrm{H}$-gel by the difference in gel formation, which is related to the detection of $\alpha$-actinin in the supernatant of pressurized actomyosin. The ultrastructural observations showed a regular filamentous network structure in the P-gel. For the sensory evaluation, the P-gels were determined to be more lustrous, juicier, more moderately elastic and smoother. These gels conformed to the criteria of Dietary Uses for Dyspahgic Patients and Japanese Dysphagia Diet 2013. High pressure treatment denatured the protein composition of the minced fish meat gel, which led to a clearer three-dimensional network structure. High pressure made it possible to form minced fish meat gels with a low salt concentration. Obtained minced fish meat gels were improved in textural properties by addition of water and under high pressure, which were different from the ones by traditional heating. Improvement in textural properties will raise the sensory evaluation for elderly and dysphagic people. It is expected that the pressurized gels will be practical for a dysphagia diet.

\footnotetext{
${ }^{*}$ Corresponding author.
}

How to cite this paper: Yoshioka, K., Yamamoto, A., Matsushima, Y., Hachisuka, K. and Ikeuchi, Y. (2016) Effects of High Pressure on the Textural and Sensory Properties of Minced Fish Meat Gels for the Dysphagia Diet. Food and Nutrition Sciences, 7, 732-742. http://dx.doi.org/10.4236/fns.2016.79074 


\section{Keywords}

\section{Minced Fish Meat Gel, High Pressure, Textural Properties, Sensory Evaluation, Dysphagia Diet}

\section{Introduction}

In recent years, the number of people who have difficulty with mastication or swallowing has increased due to the drop in physiology arising from aging or cerebral vascular disorders and neuromuscular diseases. These conditions correspond from 1 to 5 on the Dysphagic Severity Scale which indicates the decrease of the food acceptability [1]. People who have these conditions have difficulty with food intake and are liable to suffer from protein energy malnutrition. Bouziana S. D. and Tziomalos K. [2] also reported that difficulty with food intake causes protein energy malnutrition, but this is capable of being improved by having a texture-modified diet, which can lead to an increase in food intake (Germain, Dufresne, and Gray-Donald [3]). Therefore, the development of foods that are of assured nutritional value and are easy to swallow would be of great benefit to dysphagic patients and the elderly.

High-pressure treatment of food has been commercially used as a new food-processing technology. Meat researchers have also applied high pressure to meat, and they not only extended the shelf life of meat products but also modified the functionality of muscle protein systems found in emulsion-type products (e.g. sausage) (Suzuki and Macfarlane [4]; Ikeuchi, Yoshioka, and Suzuki [5]; Sikes, Tobin, and Tume [6]). Previously, we reported that high-pressure treatment had the benefit of producing a pressure-treated fish gel with a smooth texture and moderate elasticity without heat processing, (Yoshioka and Yamada 2002 [7]). High pressure treatment has also been successfully used to develop pork meat gel for a dysphagia diet (Tokifuji, Matsushima, Hachisuka, and Yoshioka [8], 2013). We were the first to demonstrate the utility of pressurization in creating a dysphagia meat diet, but the pressurized pork gel required an additional heating process after pressurization to prevent microbiological hazards. With regard to meat preference, it has been reported that people younger than 40 years of age prefer eating meat compared to fish, whereas people over 50 years of age tend to prefer fish (National Health and Nutrition Survey in Japan, Health and Welfare Statistics Association, 2010 [9]). One of the merits of eating a considerable amount of fish is a reduction in the risk of coronary heart disease due to the rich abundance of n-3 fatty acids in fish (Iso, Kobayashi, Ishihara, Sasaki et al., 2006 [10]; Virtanen, Mursu, Voutilainen, and Tuomainen, 2009 [11]).

The purpose of this study was to produce a tasty and highly nutritious fish meat product that is suitable for a dysphagia diet using high pressure treatment and to determine some of the developmental conditions that improve its sensory characteristics. We discussed the effects of heating alone, pressure alone and low salt addition on the protein composition, the ultrastructure and the textural properties of the minced fish meat gels. Furthermore we investigated whether this fish meat gel could be adapted for a dysphagia diet, judging from Food for Special Dietary Uses for Dysphagic Patients [12] and Japanese Dysphgia Diet 2013 [13].

\section{Materials and Methods}

\subsection{Preparation of the Minced Fish Meat Gels}

Fresh horse mackerel (Trachurus japonicas, 130 to150 g/around) was purchased from a market, filleted and stored at $-30^{\circ} \mathrm{C}$ for 3 months. Before the experiment, the fillets were immersed in running water at $5^{\circ} \mathrm{C}$ until the central part of the fillet was $-1^{\circ} \mathrm{C}$. The skins of the fillets were peeled and ground into minced meat by a fiber mixer (MX-X53, Panasonic Co., Japan). We intended to prepare three types of gels: the 1:0.5 gels were almost the same in hardness as the one on the market, the 1:1 gels would be formed soft gels and the 1:1.5 gels would be somehow kept their formation of gel. In a preliminary test, the ratio of water to minced fish meat was gradually increased, and the final ratios of minced fish meat and water were 1:0.5 (w/w), 1:1 (w/w) and 1:1.5 (w/w) with $1.5 \% \mathrm{NaCl}$ and mixed at $5^{\circ} \mathrm{C}$ for $3 \mathrm{~min}$, followed by placing them in cases (30 mm wide $\times 200 \mathrm{~mm}$ long). Half of the meat was heated in boiling water until the central region of the sample reached $80^{\circ} \mathrm{C}$ for approximately $10 \mathrm{~min}\left(\mathrm{H}\right.$-gel); the other meat portions (P-gel) were pressurized at $400 \mathrm{MPa}$ for $20 \mathrm{~min}$ at $17^{\circ} \mathrm{C} \pm 2^{\circ} \mathrm{C}$ using a pressurized food testing machine (MFP-7000, Mitsubishi Heavy Industries Ltd., Japan). 


\subsection{Determination of the Textural Properties}

The textural properties (hardness $\left[\mathrm{N} / \mathrm{m}^{2}\right]$, cohesiveness and adhesiveness $\left[\mathrm{J} / \mathrm{m}^{3}\right]$ ) of the $\mathrm{H}$ - and P-gels were measured with a creepmeter (RE2-33005S, Yamaden, Japan). The test conditions involved a 20-mm diameter plunger, a speed of $1 \mathrm{~mm} / \mathrm{s}$ and a deformation rate of $70 \%$. The same measurement was repeated three times. Texture was evaluated according to the dietary criteria listed in "Food for Special Dietary Uses for Dysphagic Patients (2009)" provided by the Ministry of Health, Labor and Welfare in Japan [12].

\subsection{Analysis of the Gel Protein Composition by SDS-PAGE}

To examine the protein composition, the minced fish meat gels and an actomyosin (AM) gel were electrophoresed. AM was extracted from horse mackerel meat using a Weber-Edsall solution according to the procedure of Briskey and Fukuzawa [14]. The protein concentration of the extracted AM was measured using the bicinchoninic acid (BCA) method and was adjusted to $15 \mathrm{mg} / \mathrm{mL}$ (pH 6.0). The salt concentration of the AM was adjusted to $0.26 \mathrm{M} \mathrm{KCl}$, corresponding to $1.5 \% \mathrm{NaCl}$ in horse mackerel meat. The extracted AM was divided into two halves, each of which underwent the appropriate process to obtain an AM that was heat-treated (H-AM) or pressure-treated (P-AM). The untreated AM, H-AM, P-AM, 1:1 H-gel and 1:1 P-gel were separated into supernatants and sediments using centrifugation $\left(700 \times \mathrm{g}, 10 \mathrm{~min}, 4^{\circ} \mathrm{C}\right)$. The sediment was dissolved using $500 \mu \mathrm{l}$ of a sodium dodecyl sulfate (SDS) buffer (0.12 M Tris-HCl, $0.25 \mathrm{M}$ EDTA, and 12.5\% SDS). An ultrasonic treatment was performed. The same amount of sample buffer ( $0.5 \mathrm{M}$ Tris-HCl, 2\% SDS, 5\% 2-ME, 40\% glycerol, and $0.02 \%$ BPB) was added to each sample of supernatant and sediment, and these samples were heated for 3 min in boiling water. Aliquots of the heated samples ( $30 \mu \mathrm{l}$ of supernatant fluids and $3 \mu \mathrm{l}$ of pellets) were loaded on polyacrylamide gels (10\% - 20\%). Sodium dodecyl sulfate polyacrylamide gel electrophoresis (SDS-PAGE) was performed according to the methodology described by Laemmli [15] using an electrophoretic apparatus (AE-8450, Atto. Co., Japan). Electrophoresis of the concentrated gels was conducted at a current of $10 \mathrm{~mA}$ and a voltage of $210 \mathrm{~V}$, whereas that of the resolving gels was conducted at a current of $20 \mathrm{~mA}$ and the same voltage. After electrophoresis, the gels were stained with Coomassie brilliant blue (CBB R-250) for $1 \mathrm{~h}$ and destained with a decolorization solution for $2 \mathrm{~h}$.

\subsection{Ultrastructural Observation of Extracted Actomyosin and Minced Fish Meat Gels}

The ultrastructures of actomyosin and the 1:1 H- and P-gels were fixed with half-strength Karnovsky, followed by post-fixation with 1\% osmium tetroxide (Yoshioka and Yamamoto [16]). After dehydration in graded 50\% $10 \%$ ethanol, samples were freeze-dried and coated with gold. Each sample was observed by scanning electron microscopy (S-3000N, HITACHI, Japan).

\subsection{Sensory Evaluation}

Thirteen healthy female subjects between 21 and 24 years of age provided sensory evaluation of the 1:0.5, 1:1 $\mathrm{H}-$ and P-gels, rating 11 aspects on a five-point scale: luster $(-2$ : bad to +2 : good), well-heated $(-2$ : bad to +2 : good), flavor ( -2 : bad to +2 : good), aftertaste $(-2$ : bad to +2 : good), salty $(-2$ : well-salted to +2 : salty), softness $(-2$ : hard to +2 : soft), elasticity ( -2 : slightly elastic to +2 : elastic), smoothness $(-2$ : coarse to +2 : smooth), density ( -2 : rough to +2 : fine), juiciness ( -2 : not juicy to +2 : juicy) and overall acceptance ( -2 : bad to +2 : good). Additionally in the $1: 1$ and $1: 1.5 \mathrm{H}$ - and P-gels the aspect of "easiness to mash by the tongue" was also evaluated, including the above and they were evaluated on a seven-grade scale by the same testers. The samples were served at random to avoid position effects. The tests were conducted at a room temperature of $22^{\circ} \mathrm{C}$ to $23^{\circ} \mathrm{C}$ in the Sensory Testing Laboratory at Nakamura Gakuen University. This study was approved by the in-house ethics committee of Nakamura Gakuen University, and the experiments were performed in accordance with the Declaration of Helsinki after obtaining informed consent from all subjects.

\subsection{Statistical Analysis}

The data were analyzed using SPSS 20.0J statistical software (SPSS, Inc., Chicago, USA). The differences in textural properties were tested by analysis of variance (ANOVA), followed by Tukey's multiple range test. The Games-Howell's multiple range test was used for analysis of the sensory evaluation test. The differences were determined to be significant for $p$ values less than 0.05 . 


\section{Results}

\subsection{Textural Properties of the Minced Fish Meat Gels}

The textural properties of the minced fish meat gels are shown in Figure 1. The hardness values were 0.97 to $2.83\left[\times 10^{4} \mathrm{~N} / \mathrm{m}^{2}\right]$ in the H-gels and 2.25 to $10.03\left[\times 10^{4} \mathrm{~N} / \mathrm{m}^{2}\right]$ in the P-gels. The hardness values in the P-gels were shown to be 2.3 to 3.6 times as high as those in the H-gels. The hardness values of the 1:0.5 and 1:1 P-gels were higher compared to those of the H-gels ( $p<0.05$ ). The hardness values were reduced to $34 \%$ in the H-gels and to $23 \%$ in the P-gels when the ratio of water and minced fish meat changed from 1:0.5 to 1:1. The cohesiveness ranged from 0.195 to 0.298 in the H-gels and from 0.355 to 0.603 in the P-gels. The adhesiveness values of the 1:0.5 and 1:1 H-gels were higher than those of the 1:0.5 and 1:1 P-gels.

\subsection{Gel Protein Composition}

The SDS-PAGE pattern of the supernatant and the sediment of actomyosin and minced fish meat gels are shown in Figure 2(a) and Figure 2(b). In the supernatant and sediment, the bands in the molecular weight region of approximately $200 \mathrm{kDa}$ (myosin heavy chain) and $42 \mathrm{kDa}$ (actin) were analyzed. In the supernatant of the Pgels, bands of troponin and tropomyosin, as well as a band that was assumed to contain myosin light chains, were found. These bands were wider than those of the H-gels. In addition to these proteins, $\alpha$-actinin bands at approximately $95 \mathrm{kDa}$ were also found in the supernatant of the P-gels.

\subsection{Changes in Ultrastructure}

Micrographs of the ultrastructure of AM and the minced fish meat gels are shown in Figure 3. The H-AM (Figure 3(a)) exhibited an irregular network structure and an uneven surface that was presumed to be due to the shrinkage of muscle fibers that are affected by heating. They also showed some breakages in the network, whereas the P-AM (Figure 3(b)) had a regular network structure. The protein in the H-gel (Figure 3(c)) was cohesive and massively affected by heating. Fat droplets and sarcoplasmic protein were adhered, whereas a fibrous network structure was detected in the P-gel (Figure 3(d)).

\subsection{Sensory Evaluation}

The results of the sensory evaluation test in the 1:0.5 H- and P-gels and the 1:1 $\mathrm{H}$ - and P-gels showed respectively in Figure 4(a) and Figure 4(b). The 1:1 P-gel was determined to be more lustrous, more elastic, smoother, more dense and juicier than the 1:1 $\mathrm{H}$-gel $(p<0.05)$. Conversely, the 1:1 $\mathrm{H}$-gel was determined to be wellheated and to taste good $(p<0.05)$. The panelists judged the 1:1 P-gel to be more acceptable. Figure 4(c) showed the result of sensory evaluation test in the 1:1 and 1:1.5 $\mathrm{H}$ - and P-gels with a seven-grade scale. The 1:1 and 1:1.5 P-gels were more elastic, smoother and more density than the H-gels. The 1:1.5 P-gel was evaluated to be easy to mash by the tongue.
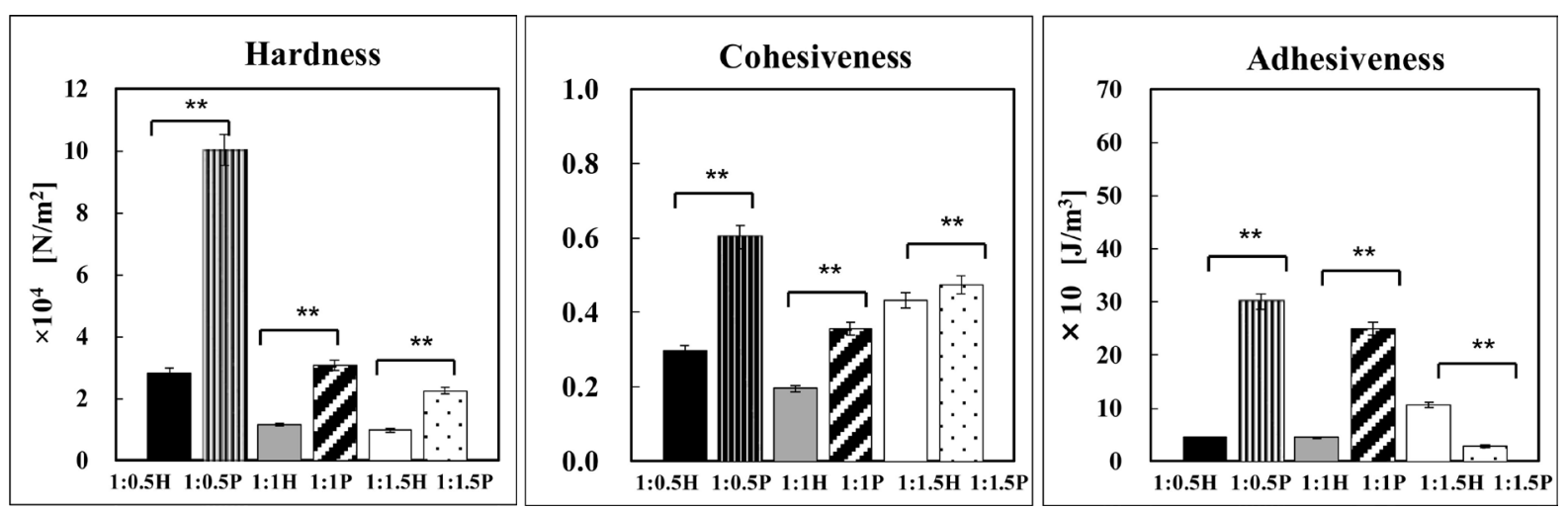

Figure 1. Textural properties of 1:0.5, $1: 1$ and 1:1.5 minced fish meat gels. H: heated gel, P: pressurized gel, Measuring condition: plunger; $20 \mathrm{~mm} \varphi$; deformation rate, $70 \%$; test speed, $10 \mathrm{~mm} / \mathrm{sec}$. Mean $\pm \mathrm{SD} ; \mathrm{n}=6$; ${ }^{* *}$ Significantly different (p < 0.01 ) as assessed by Tukey’s multiple range test. 


\section{Discussion}

In this study, textural properties (Figure 1 and Table 1) were used as a physical parameter of minced fish meat gels because hardness, adhesiveness and cohesiveness are the criteria for the physical properties in the "Food for Special Dietary Uses for Dysphagic Patients (2009)" [12] provided by the Consumer Affairs Agency, Government of Japan. The textural properties of each minced fish meat gel were classified according to the "Food for Special Dietary Uses for Dysphagic Patients", which indicates that hardness, cohesiveness and adhesiveness are important. The values in hardness of the H-gels were from 0.97 to $2.83\left[\times 10^{4} \mathrm{~N} / \mathrm{m}^{2}\right]$ and the ones of the P-gels were from 2.25 to $10.03\left[\times 10^{4} \mathrm{~N} / \mathrm{m}^{2}\right]$. The hardness in the P-gels showed significantly higher than the H-gels in each ratios of gels. In adhesiveness the values of the H-gels showed higher along with the addition of water. The adhesiveness of the 1:1.5 H-gel decreased much more than the 1:0.5 P-gel. The hardness of the 1:1.5 H-gel was within the diet criteria II (second). The hardness of the 1:1 H- and 1:1.5 P-gels were conformed to the diet criteria III (third).

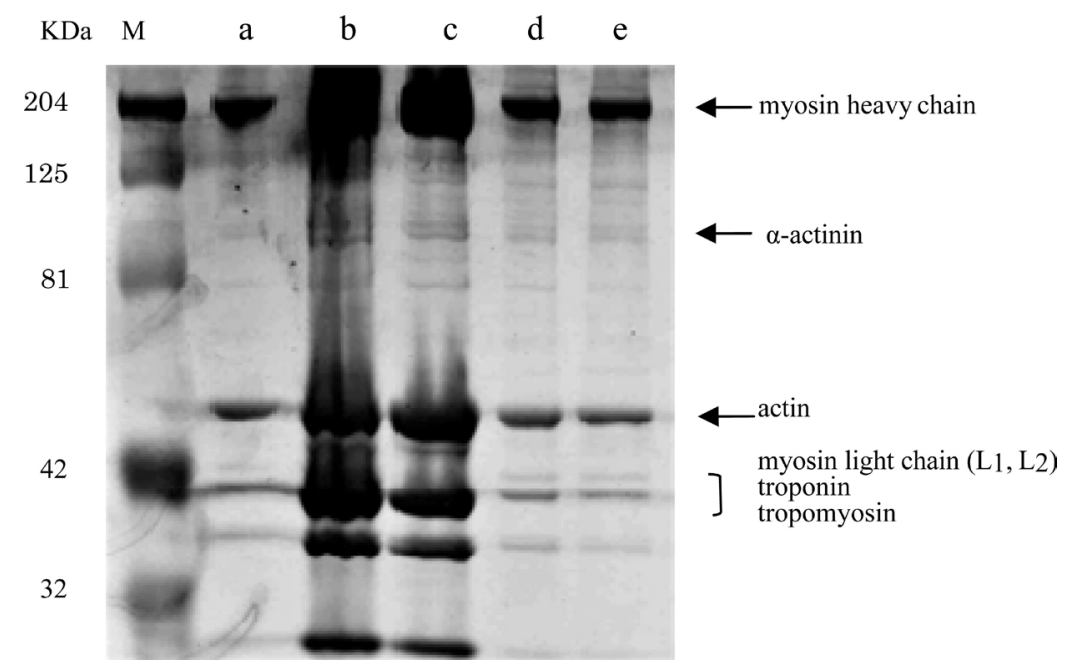

(a)

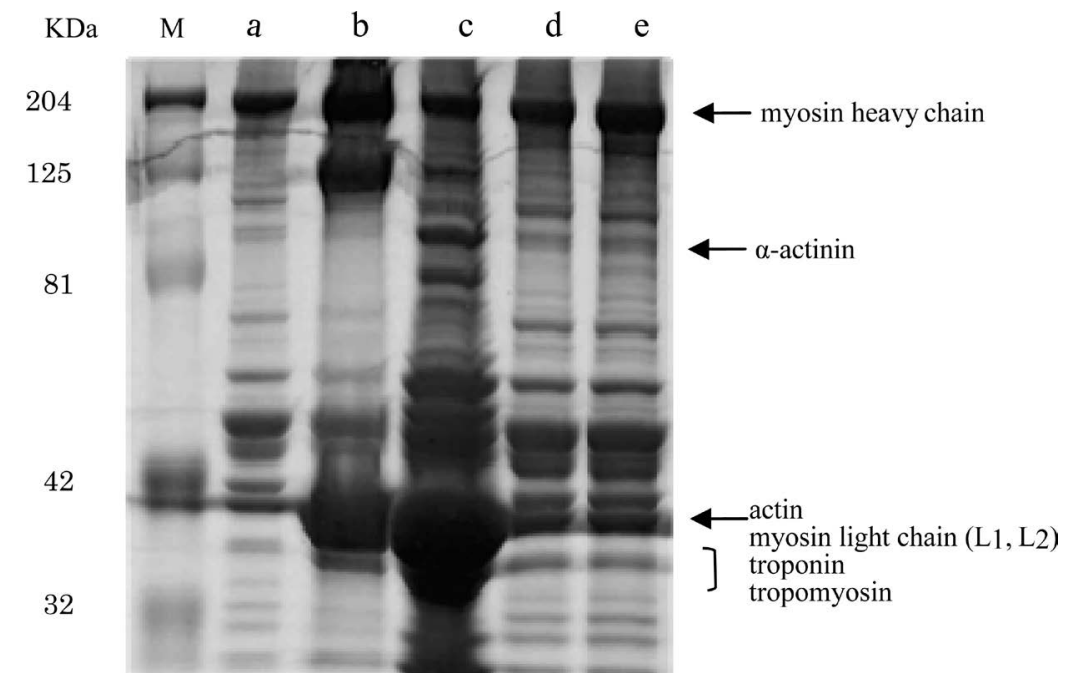

(b)

Figure 2. (a) SDS-PAGE patterns of heated and pressurized actomyosin extracts from fish meat. Abbreviations are as follows: a, raw actomyosin; b, supernatant of the heated actomyosin; c, supernatant of the pressurized actomyosin; d, sediment of the heated actomyosin; e, sediment of the pressurized actomyosin; M, molecular weight marker. (b) SDS-PAGE patterns of heated and pressurized minced fish meat gels. Abbreviations are as follows: $a$, raw minced fish meat gel; b, supernatant of the heated gel; c, supernatant of the pressurized gel; d, sediment of the heated gel; e, sediment of the pressurized gel; M, molecular weight marker. 

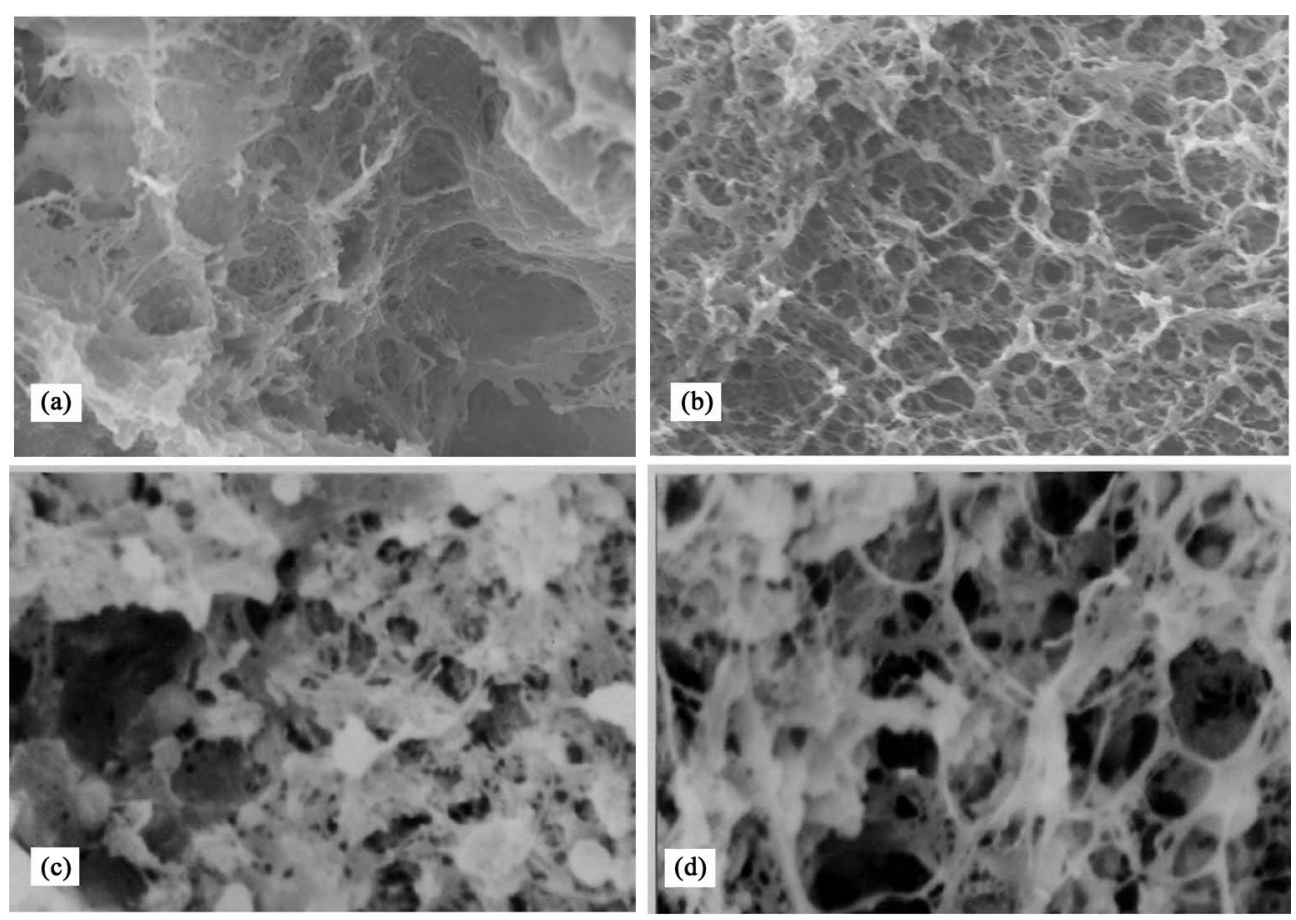

$(\times 5,000)$

Figure 3. Ultrastructure of actomyosin extracts from fish meat and the minced fish meat gels. (a) Heated actomyosin in boiling waterfor $10 \mathrm{~min}$ at $80^{\circ} \mathrm{C}$; (b) Pressurized actomyosin at $400 \mathrm{MPa}$ for $20 \mathrm{~min}$; (c) Heated minced fish meat gel with $1.5 \% \mathrm{NaCl}$ heated in boiling water for $10 \mathrm{~min}$ at $80^{\circ} \mathrm{C}$; (d) Pressurized minced fish meat gel $1.5 \% \mathrm{NaCl}$ pressurized at 400 MPa for $20 \mathrm{~min}$.

With regard to the textural properties of minced fish meat gels, the values of hardness for the 1:0.5 and 1:1 P-gels were higher than those for the H-gels, which differed from the gel formation mechanism of myosin. With regard to the participation of actin in gel formation, filamentous F-actin is de-polymerized into monomeric G-actin under pressure treatment (Ikeuchi, Suzuki, Oota et al., 2002 [17]), and it is thought that the volume changes and the subsequent molecular association participates in affecting the gel strength along with depolymerization.

High pressurization changes protein liquid into the state of coagulation or gel, which is different from protein product treated only by heating. The open reaction of the covalent bond of protein is not changed by high pressurization, but the non-covalent bond is changed into protein with deformation of three-dimensional structures. (Sun X. D. \& Holley R. A. [18]).

Myosin exists as a monomer at high salt concentrations of over $0.4 \mathrm{M} \mathrm{KCl}$ and exists as a filament at a low salt concentration below 0.4 M KCl at a pH of 6.0 (Yamamoto and Hayashi, 1993 [19]). Because monomeric myosin molecules do not form a pressurized gel (Yamamoto, Yoshida, Morita, and Yasui, 1994 [20]), it is assumed that the filamentous myosin in fish meat gel added to $1.5 \% \mathrm{NaCl}$ is denatured under pressurization by the formation of a gel through lateral and intersectional associations on the surface. However, it was reported that gel formation by heating with a low salt concentration occurred using the same mechanism.

SDS-PAGE (Figure 2(a) and Figure 2(b)) was conducted to compare the protein structures of the $\mathrm{H}$ - and P-gels. The dissociation of low molecular weight proteins and $\alpha$-actinin was more common in the P-gels than in the H-gels. In vitro analysis indicated that the functions of $\alpha$-actinin are to facilitate the creation of F-actin by advancing the polymerization of G-actin and to create cross bridges for F-actin. These functions serve to anchor filaments that are composed of actin, tropomyosin, and troponin (Holmes, Goll, and Suzuki [21]), and under high-pressure treatment, free $\alpha$-actinin has been observed in myosin that was extracted from the skeletal muscle of laboratory rabbits (Suzuki, Suzuki, and Ikeuchi [22]). Free $\alpha$-actinin was also observed in the present study, suggesting that the high-pressure treatment weakened the network structures and that tropomyosin and troponin were solubilized. 


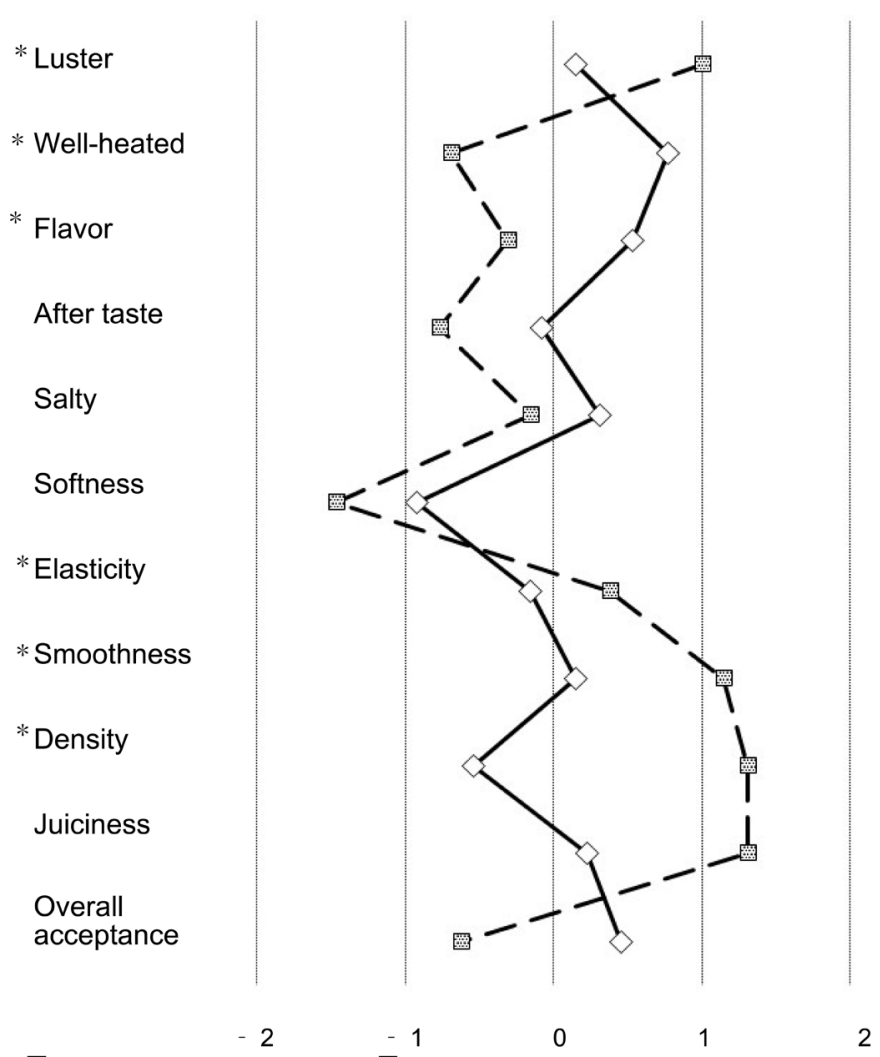

$\square$ :Heated minced fish meat gels

: Pressurized minced fish meat gels, *: significantly different $(p<0.05)$

(a)

* Luster
* Well-heated
* Flavor
* After taste
* Salty
* Softness
* Elasticity
* Smoothness
* Density
* Juiciness
* Overall
acceptance

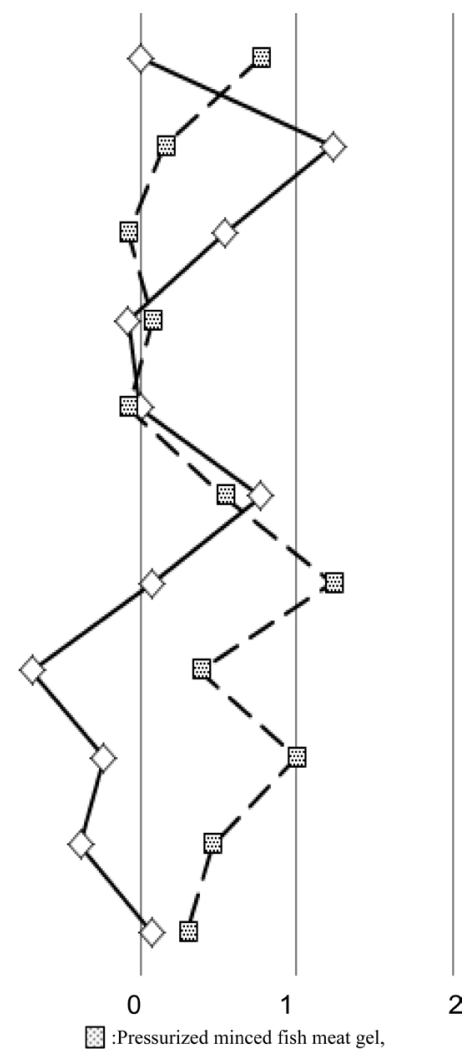

(b) 
Luster

Well-heated

Salty

After taste

Hardness

Elasticity

Smoothness

Density

Easiness to swallow

\section{Easiness to mash by \\ the tongue}

\section{Overall acceptance}
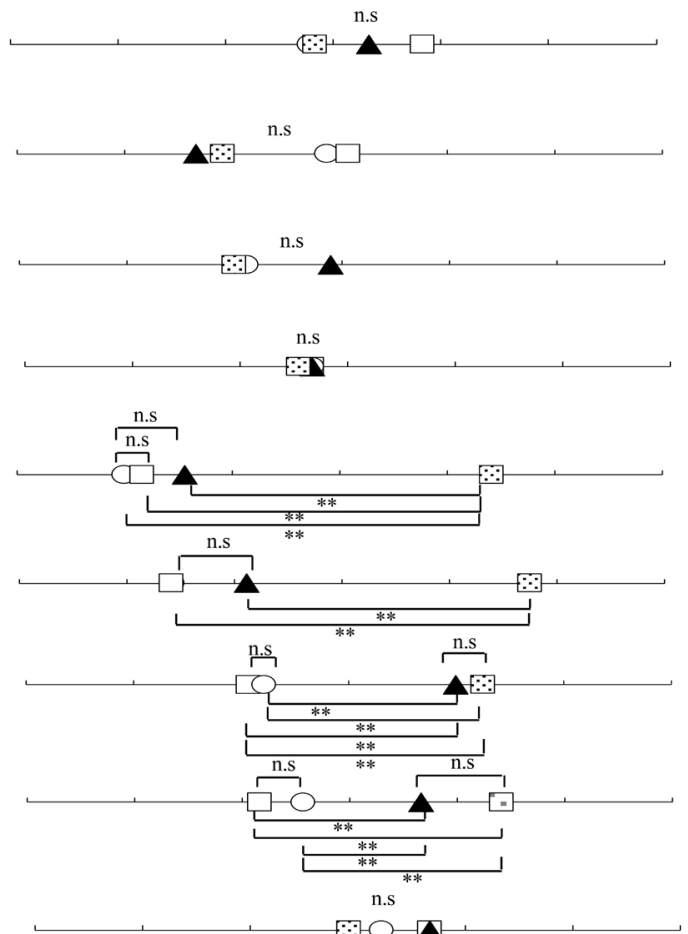

$\because$

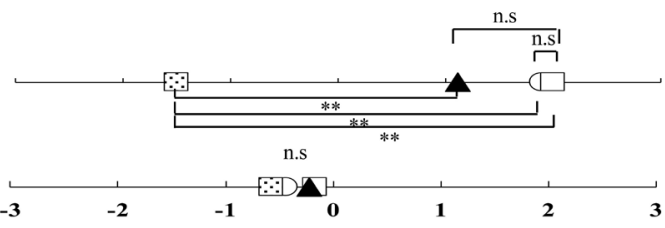

$\square$ 1:1 H $\because 1: 1 \mathrm{P} \quad \bigcirc 1: 1.5 \mathrm{H} \triangle 1: 1.5 \mathrm{P}$

(c)

Figure 4. (a) Sensory evaluation test of 1:0.5 heated and pressurized minced fish meat gels; (b) Sensory evaluation test of 1:1 heated and pressurized minced fish meat gels. Thirteen healt female subjects 21 to 24 years of age underwent sensory evaluation tests on a five-point scale. ${ }^{*}$ Significantly different $(p<0.05)$; (c) The sensory evaluation test of 1:1 and 1:1.5 heated and pressurized gels. Samples are 1:1 and 1:1.5 heated and pressurized gels with $1.5 \% \mathrm{NaCl}$. Sensory evaluation test was examined by 13 testers from 21 to 24 years of age with a seven-grade scale. Significantly different $\left({ }^{* *} \mathrm{p}<0.01\right)$ as assessed by Games-Howell's multiple range test.

Table 1. The textural properties of the diet criteria for dysphagic patients by the consumer affairs agency in Japan.

\begin{tabular}{lccc}
\hline & I & II & III \\
\hline Hardness $\left(\mathrm{N}^{\prime} \mathrm{m}^{2}\right)$ & $2.5 \times 10^{3} \sim 1.0 \times 10^{4}$ & $1 \times 10^{3} \sim 1.5 \times 10^{4}$ & $3 \times 10^{2} \sim 2 \times 10^{4}$ \\
\hline Adhesiveness $\left(\mathrm{J} / \mathrm{m}^{3}\right)$ & $4 \times 10^{2}$ or less & $1 \times 10^{3}$ or less & $1.5 \times 10^{3}$ or less \\
\hline Cohesiveness & $0.2 \sim 0.6$ & $0.2 \sim 0.9$ & - \\
\hline & 仓 & 仓 \\
\hline $\begin{array}{c}1: 1.5 \mathrm{H} \text { gel fits } \\
\text { the criteria II }\end{array}$ & $\begin{array}{c}1: 1 \mathrm{P}, 1: 1 \mathrm{H}, \text { and } 1: 1.5 \mathrm{P} \\
\text { gels fit the criteria III }\end{array}$
\end{tabular}

It has been reported that divalent metal ion binding with protein is dissociated and the formation of salt bridges between myofibrillar proteins is accelerated under high-pressure treatment (Crehan, Troy, and Buckkley [23]; Ikeuchi, Tanji, Kim, and Suzuki [24]; Ikeuchi, Yoshioka, and Suzuki [5]). At a low salt concentration of 
$1.5 \% \mathrm{NaCl}(0.26 \mathrm{M})$, the gel formation of fish protein was improved by high pressure treatment, which could occur in the production of fish meat products with low levels of additives, such as salt, sodium chloride and sodium phosphate.

In the ultrastructure of the actomyosin extracted from minced fish meat, heated actomyosin (Figure 3(a)) had an irregular network with some breakages; it contained the aggregated-type gel structure in which coagulations were roughly connected. The pressurized form had a regular network and exhibited the stranded type gel structure reported by Yamamoto K. et al. [25]. Based on these results, it is obvious that myosin filamentous gel was formed by actin depolymerization in the fibrous network structure observed in the P-gel (Figure 3(d)). This is considered to be formed by irregular lateral associations of filaments along with denaturing by pressure.

In a sensory evaluation test (Figure 4), the 1:1 P-gel was determined to have higher elasticity, smoothness, and density in its textural properties compared to the1:1 H-gel. Considering the SEM observations and the textural properties, the softness, moderate elasticity and smoothness in the sensory evaluation of the 1:1 P-gel were caused by the water-retaining capacity in the network structure under pressure treatment.

Comparing the results of each gel with the items in the table of "the modified diet for dysphagic persons in 2013" from the Japanese Society of Dysphagia Rehabilitation [13], the H- and P-gels were consistent with 3 and 4 of the modified diet (code 3 to 4 ) respectively. It suggests that pressurized minced fish meat gel could be part of the dysphagia diet for dysphagic persons [26] [27].

\section{Conclusion}

The 1:1 and 1:1.5 pressurized gels contained a significant amount of water, and the protein composition was denatured by high pressurization, leading to a three-dimensional network structure that was more clearly formed. It is understood that water can be included in the framework of networks formed by pressurization. The 1:1 and 1:1.5 pressurized gels were evaluated to be moderately elastic and smooth gels. Additionally, at low salt concentrations, the minced fish meat gel may be produced by high pressure treatment. Furthermore the 1:1 and 1:1.5 pressurized gels were satisfied with both the criteria of Food for Special Dietary Uses for Dysphagic Patients and Japanese Dysphgia Diet 2013. Therefore it is thought that the 1:1 and 1:1.5 pressurized gels would be suitable for individuals who have difficulty with mastication and swallowing. Fish meat protein gel induced by pressurization will be marketable, and it is expected to be useful for a dysphagia diet and for elderly individuals.

\section{References}

[1] The National Center for Geriatrics and Gerontology (NCGG) (2012) Research Business Report Pertaining to the Dysphagia, 2011. Old Health Business Promotion Expenses Subsidy Money Nursing Health Promotion and Business, 10.

[2] Bouziana, S.D. and Tziomalos, K. (2011) Malnutrition in Patients with Acute Stroke. Journal of Nutrition and Metabolism, 2011, Article ID: 167898. http://www.ncbi.nlm.nih.gov/pmc/articles/PMC3255318/ http://dx.doi.org/10.1155/2011/167898

[3] Germain, I., Dufresne, T. and Gray-Donald, K. (2006) Novel Dysphagia Diet Improves the Nutrient Intake of Institutionalized Elders. Journal of American Diet Association, 106, 1614-1623.

http://www.andjrnl.org/article/S0002-8223(06)01696-8/references http://dx.doi.org/10.1016/j.jada.2006.07.008

[4] Suzuki, T. and Macfarlane, J.J. (1984) Modification of the Heat-Setting Characteristics of Myosin by Pressure Treatment. Meat Science, 11, 263-274. http://europepmc.org/abstract/MED/22055000 http://dx.doi.org/10.1016/0309-1740(84)90057-3

[5] Ikeuchi, Y., Yoshioka, K. and Suzuki, A. (2006) Recent Advanced Topics on Application of High Pressure Technology to Meat Processing. The Review of High Pressure Science and Technology, 16, 17-25. http://dx.doi.org/10.4131/jshpreview.16.17

[6] Sikes, L.A., Tobin, B.A. and Tume, K.R. (2009) Use of High Pressure to Reduce Cook and Improve Texture of LowSalt Beef Sausage Batters. Innovative Food Science and Technologies, 10, 405-412. http://www.sciencedirect.com/science/article/pii/S1466856409000265 http://dx.doi.org/10.1016/j.ifset.2009.02.007

[7] Yoshioka, K. and Yamada, A. (2002) Textural Properties and Sensory Evaluation of Soft Surimi Gel Treated by High Pressurization. Trends in High Pressure Bioscience and Biotechnology, 19, 475-480. http://store.elsevier.com/Trends-in-High-Pressure-Bioscience-and-Biotechnology/isbn-9780080543222/ http://dx.doi.org/10.1016/s0921-0423(02)80141-1 
[8] Tokifuji, A., Matsushima, Y., Hachisuka, K. and Yoshioka, K. (2013) Texture, Sensory and Characteristics of HighPressure-Heat-Treated Pork Meat Gel as a Dysphagia Diet. Meat Science, 93, 843-848.

http://europepmc.org/abstract/MED/23313970

http://dx.doi.org/10.1016/j.meatsci.2012.11.050

[9] Health and Welfare Statistics Association (2010) Journal of Health and Welfare Statistics, 57-37.

[10] Iso, H., Kobayashi, M., Ishihara, J., Sasaki, S., Okada, K., Kita, Y., Kokubo, Y. and Tsugane, S., JPHC Study Group (2006) Intake of Fish and n3 Fatty Acids and Risk of Coronary Heart Disease among Japanese. The Japan Public Health Center-Based (JPHC) Study Cohort I. Circulation, 113, 195-202. http://www.ncbi.nlm.nih.gov/pubmed/16401768 http://dx.doi.org/10.1161/CIRCULATIONAHA.105.581355

[11] Virtanen, J.K., Mursu, J., Voutilainen, S. and Tuomainen, T.P. (2009) Serum Long-Chain n-Polyunsaturated Fatty Acids and Risk of Hospital Diagnosis of Atrial Fibrillation in Men. Circulation, 120, 2315-2321.

http://www.ncbi.nlm.nih.gov/pubmed/19933935 http://dx.doi.org/10.1161/CIRCULATIONAHA.109.852657

[12] Ministry of Health, Labour and Welfare (2009) Food with Health Claims, Food for Special Dietary Uses, and Nutrition Labeling. http://www.mhlw.go.jp/english/topics/foodsafety/fhc/03.html

[13] Japan Feeding of Dysphagia Rehabilitation Association Medical Committee (2013) Japan Eating Swallowing Rehabilitation of Swallowing Adjustment Classified 2013. Journal of Japan Eating Dysphagia Rehabilitation, 173, 255-267.

[14] Briskey, E.J. and Fukazawa, F. (1971) Myofibrilar Proteins of Skeletal Muscle. Advances in Food Research, 19, 279360. http://dx.doi.org/10.1016/S0065-2628(08)60034-8

[15] Laemmli, U.K. (1970) Cleavage of Structural Proteins during the Assembly of the Head of Bacteriophage T4. Nature, 227, 680-684. http://www.ncbi.nlm.nih.gov/pubmed/5432063 http://dx.doi.org/10.1038/227680a0

[16] Yoshioka, K. and Yamamoto, T. (1998) Changes of Ultrastructure and the Physical Properties of Carp Muscle by High Pressurization. Fisheries Science, 64, 89-94. https://www.jstage.jst.go.jp/article/fishsci1994/64/1/64_1_89/_article/references/-char/ja/

[17] Ikeuchi, Y., Suzuki, A., Oota, T., Hagiwara, K., Tatsumi, R., Ito T., et al. (2002) Fluorescence Study of the High Pressure-Induced Denaturation of Skeletal Muscle Actin. The FEBS Journal, 269, 364-371. http://onlinelibrary.wiley.com/doi/10.1046/j.0014-2956.2001.02664.x/full http://dx.doi.org/10.1046/j.0014-2956.2001.02664.x

[18] Sun, X.D. and Holley, R.A. (2010) High Hydrostatic Pressure Effects on the Texture of Meat and Meat Products. Journal of Food Science, 75, R17-R23. http://www.ncbi.nlm.nih.gov/pubmed/20492191 http://dx.doi.org/10.1111/j.1750-3841.2009.01449.x

[19] Yamamoto, K., Hayashi, S. and Yasui, T. (1993) Hydrostatic Pressure-Induced Aggregation of Myosin Molecules in $0.5 \mathrm{M} \mathrm{KCl}$ at pH 6.0. Bioscience, Biotechnology, and Biochemistry, 57, 383-389.

http://www.tandfonline.com/doi/abs/10.1271/bbb.57.383 http://dx.doi.org/10.1271/bbb.57.383

[20] Yamamoto, K., Yoshida, Y., Morita, J. and Yasui, T. (1994) Morphological and Physicochemical Changes in the Myosin Molecules Induced by Hydrostatic Pressure. Journal of Biochemistry, 116, 215-220.

http://jb.oxfordjournals.org/content/116/1/215.full.pdf\#search='Morphological+and++physicochemical+changes+in+th e+myosin+molecules+induced+by+hydrostatic

[21] Holmes, G.R., Goll, D.E. and Suzuki, A. (1971) Effect of $\alpha$-Actinin on Actin Viscosity. Biochimica et Biophysica Acta (BBA)-Bioenergetics, 253, 240-253.

[22] Suzuki, A., Suzuki, N. and Ikeuchi, Y. (1991) Effect of High Pressure Treatment on the Ultrastructure and Solubilization of Isolated Myofibrils. Agricultural and Biological Chemistry, 55, 2467-2473. http://www.tandfonline.com/doi/abs/10.1080/00021369.1991.10871015

[23] Crehan, C.M., Troy, D.J. and Buckley, D.J. (2000) Effects of Salt Level and High Hydrostatic Pressure Processing on Frankfruters Formulated with 1.5 and 2.5\% Salt. Meat Science, 55, 123-130.

http://www.ncbi.nlm.nih.gov/pubmed/22060912 http://dx.doi.org/10.1016/S0309-1740(99)00134-5

[24] Ikeuchi, Y., Tanji, H., Kim, K. and Suzuki, A. (1992) Dynamic Rheological Measurement on Heat-Induced Pressurized Actomyosin Gels. Journal of Agricultural and Chemistry, 40, 1751-1755.

http://pubs.acs.org/doi/abs/10.1021/jf00022a005 http://dx.doi.org/10.1021/jf00022a005

[25] Yamamoto, K., Miura, T. and Yasui, T. (1990) Gelation of Myosin Filament under High Hydrostatic Pressure. Food 
Structure, 9, 269-277.

[26] Cichero, J.A.Y., Steele, C., Duivestein, J., Clavé, P., Chen, J.S., Kayashita, J., Dantas, R., Lecko, C., Speyer, R., Lam, P. and Murray, J. (2013) The Need for International Terminology and Definitions for Texture-Modified Foods and Thickened Liquids Used in Dysphagia Management: Foundations of a Global Initiative. Current Physical Medicine and Rehabilitation Reports, 1, 280-291. http://dx.doi.org/10.1007/s40141-013-0024-z

[27] Steele, C.M., et al. (2015) The Influence of Food Texture and Liquid Consistency Modification on Swallowing Physiology and Function: A Systematic Review. Dysphagia, 30, 2-26.

http://link.springer.com/article/10.1007/s00455-014-9578-x http://dx.doi.org/10.1007/s00455-014-9578-x

\section{Submit or recommend next manuscript to SCIRP and we will provide best service for you:}

Accepting pre-submission inquiries through Email, Facebook, Linkedin, Twitter, etc A wide selection of journals (inclusive of 9 subjects, more than 200 journals)

Providing a 24-hour high-quality service

User-friendly online submission system

Fair and swift peer-review system

Efficient typesetting and proofreading procedure

Display of the result of downloads and visits, as well as the number of cited articles

Maximum dissemination of your research work

Submit your manuscript at: http://papersubmission.scirp.org/ 